\title{
Heritability of Renal Function and Inflammatory Markers in Adult Male Twins
}

\author{
Paolo Raggi ${ }^{a, b}$ Shaoyong Su ${ }^{a-c}$ Cristina Karohl ${ }^{a, b}$ Emir Veledar ${ }^{a-c}$ \\ Enrique Rojas-Campos ${ }^{\text {a, }}$ Viola Vaccarino ${ }^{a-c}$ \\ ${ }^{a}$ Division of Cardiology and Department of Medicine, ${ }^{b}$ Emory Program in Cardiovascular Outcomes Research and \\ Epidemiology (EPICORE), and 'Department of Epidemiology, Rollins School of Public Health, Emory University, \\ Atlanta, Ga., USA; dUnidad de Investigación Médica en Enfermedades Renales (UIMER), CMNO, IMSS, \\ Guadalajara, Mexico
}

\section{Key Words}

Heritability $\cdot$ Renal function $\cdot$ Inflammation

\begin{abstract}
Background: Loss of renal function is accompanied by a progressive increase in markers of inflammation; it is unknown whether they share common genetic pathways. Study Design: We evaluated the shared heritability of estimated glomerular filtration rate (eGFR) and markers of inflammation and endothelial activation in 524 twin males from the Vietnam Era Twin Registry; 9 twins were excluded due to incomplete or incorrect data. Models were adjusted for age, race, body mass index, smoking, hypertension, diabetes mellitus, prior coronary artery disease and intercurrent medications. Results: The mean eGFR was $89 \pm 13 \mathrm{ml} / \mathrm{min} / 1.73 \mathrm{~m}^{2}$ (range 35-146); eGFR, intracellular adhesion molecule (ICAM) and TNF- $\alpha$ receptor (TNF- $\alpha$ R) were moderately heritable (all $\sim 50 \%$ ), while IL-6 receptor (IL-6R) and P-selectin were highly heritable (68 and $76 \%$, respectively). IL-6R and TNF- $\alpha$ R showed a significant inverse association with eGFR ( $p=0.04$ and $p<0.0001$ ) while the association with ICAM and P-selectin was direct ( $p=0.001$ and $p=0.06$ ). Bivariate structural equation models showed that the association between eGFR and biomarkers was due to unique environmental factors and there were no shared genetic pathways. Conclu-
\end{abstract}

sion: We found no shared genetic pathways between renal function and inflammation. Thus, increased inflammation represents a response to declining renal function rather than being a mechanism contributing to renal deterioration.

Copyright ๑ 2010 S. Karger AG, Basel

\section{Introduction}

The renal glomerulus is a vascular tuft and as such it may be the target of various inflammatory pathways similar to the pathways that are currently believed to be involved in atherosclerosis development. It is well known that loss of renal function is accompanied by an increase in serum levels of inflammatory markers [1-5], and some have suggested that enhanced inflammation may cause further renal damage $[6,7]$. Both renal function and inflammation have been shown separately to be heritable [8-10], but there has never been an analysis of their shared heritability. The demonstration of a shared genetic pathway between inflammation and renal function in a sample of predominantly healthy individuals may provide useful insight into whether inflammatory processes are pathophysiologically linked with the development of renal dysfunction, while the absence of a shared genetic pathway will suggest that inflammation is a response to

\section{KARGER}

(c) 2010 S. Karger AG, Basel

Fax +4161306 1234 E-Mail karger@karger.ch www.karger.com www.karger.com/ajn
Paolo Raggi, MD

Emory University School of Medicine

1365 Clifton Rd NE, AT-504

Atlanta, GA 30322 (USA)

Tel. +1 404778 5414, Fax +1 404778 3540, E-Mail praggi@emory.edu 
declining renal function. Therefore, in this study using structural equation model (SEM) analyses we examined the hypotheses that (1) there are genetic and/or environmental factors contributing to the variation of renal function and inflammation and (2) these factors are shared between these two traits in a well-characterized group of monozygotic (MZ) and dizygotic (DZ) twin veterans of the Vietnam War.

\section{Material and Methods}

\section{Study Population}

The Emory Twin Studies (ETS) pooled twin samples recruited in two companion studies: the Twins Heart Study (THS) and the Stress and Vascular Evaluation in Twins (SAVEIT). The purpose of these studies was to elucidate the role of psychological, behavioral and biological risk factors for subclinical cardiovascular disease in twins. Both projects recruited middle-aged male $\mathrm{MZ}$ and DZ twin pairs from the Vietnam Era Twin (VET) Registry, one of the largest twin registries in the United States [11]. The VET Registry includes male-male $\mathrm{MZ}$ and $\mathrm{DZ}$ twin pairs born between 1939 and 1957; both siblings served on active military duty during the Vietnam era (May 1965 to August 1975). The Registry was assembled in the mid-1980s by applying an algorithm that matched same last name, different first name, same date of birth, and similar social security numbers in a Department of Defense database of approximately 5.5 million discharged servicemen. 7,369 possible twin pairs were initially identified, and military records were examined to confirm twinship. Of the 4,774 twin pairs who were eventually located and responded to an initial questionnaire, 4,648 had zygosity confirmed and were included. Registry members are representative of all twins who served in the military during the Vietnam War from a variety of sociodemographic backgrounds. Approximately one third served in Vietnam.

THS enrolled 180 twin pairs between 2002 and 2006 [12]. SAVEIT included 82 twin pairs between 2005 and 2008, and it is ongoing. Both studies followed identical procedures, measurements and protocols. Twins included in ETS were randomly selected from the VET Registry among those born between 1946 and 1956 and were free of a self-reported diagnosis of cardiovascular disease based on survey data collected in 1990, including a previous diagnosis of myocardial infarction, coronary heart disease, angina, congestive heart failure or stroke, or previous coronary angioplasty or coronary bypass surgery. However, at the time of enrolment about $10 \%$ of the patients had developed coronary artery disease. For THS, random samples of twins in two strata were selected from the Registry: one stratum included twin pairs discordant for a lifetime history of major depression; the other stratum included twin pairs with no history of depression. For SAVEIT, a random sample of twin pairs discordant for posttraumatic stress disorder was selected. All twins traveled in pairs to Emory University and were examined at the Emory University General Clinical Research Center. All data collection occurred during a 24-hour admission under controlled conditions. Both studies were approved by the Emory Institutional Review Board, and all subjects signed an informed consent.

\section{Measurements}

All measurements were performed in the morning after an overnight fast, and both twins in a pair were tested at the same time. A medical history was obtained and a physical examination was conducted for all twins. Measured weight and height were used to calculate body mass index (BMI) as weight in kilograms divided by the height in square meters. Systolic and diastolic blood pressures were measured by mercury sphygmomanometer in the right arm, after 10 min of rest with the subject in a sitting position. The average of two measurements obtained 5 min apart was used in the analyses. Hypertension was defined as a systemic pressure $>140 / 90 \mathrm{~mm} \mathrm{Hg}$ or currently using blood pressure-lowering medications. Cigarette smoking was classified into current versus never or past smoker. Diabetes was considered present if the patients received treatment with insulin, oral hypoglycemic drugs or had a fasting glucose $>126 \mathrm{mg} / \mathrm{dl}$. Glomerular filtration rate (eGFR) was estimated using a creatinine-based formula recently published by the Chronic Kidney Disease Epidemiology Collaboration group (CKD-EPI equation) [13]. Venous blood samples were drawn after an overnight fast. Plasma was rapidly separated and immediately stored in $\mathrm{a}-80^{\circ} \mathrm{C}$ freezer until laboratory analysis. Under these conditions, assay stability is excellent for inflammatory biomarkers [14]. We measured a comprehensive spectrum of biomarkers of inflammation and endothelial cell activation, including interleukin-6 (IL-6), IL-6 soluble receptor (IL-6R), C-reactive protein, tumor necrosis factor- $\alpha$ (TNF- $\alpha$ ), the TNF- $\alpha$ soluble receptor II (TNF- $\alpha$ R), matrix metalloproteinase 2 (MMP-2), matrix metalloproteinase 9 (MMP-9), P-selectin, soluble cell adhesion molecules vascular cell adhesion molecule-1 (VCAM-1) and intracellular adhesion molecule-1 (ICAM-1), fibrinogen and white blood cell count. IL-6, IL-6R, TNF- $\alpha$, TNF$\alpha \mathrm{R}$, VCAM-1, ICAM-1, MMP-2, MMP-9 and P-selectin were assessed using commercially available ELISA kits from R\&D Systems (http://www.rndsystems.com). C-reactive protein was measured with the Beckman Coulter High Sensitivity C-Reactive Protein assay on the Synchron LX-20 analyzer (Brea, Calif., USA). White blood cell count count was measured with the Beckman Coulter LH 750 hematology analyzer (Brea, Calif., USA). Fibrinogen was measured by using the Dade Behring BCS coagulation analyzer. Serum creatinine and glucose were measured on the Beckman Coulter Synchron LX-20 chemistry analyzer. All biochemical assays for each twin pair were processed in the same analytical run.

\section{Statistical Analyses}

Initial descriptive analyses examined means and percentages of eGFR, markers of inflammation and endothelial activation, and other study variables. The generalized estimating equation model, which corrects for the correlation between co-twins, was used to assess whether there was an association between eGFR and inflammatory markers. First we performed unadjusted analyses. Then a priori specified covariates were employed for adjustment; these included age, race, BMI, current smoking, diabetes, hypertension, coronary artery disease and the following medications: aspirin, $\beta$-blockers and ACE inhibitors, angiotensin receptor blockers, and statins. Because the study sample included twins with major depression and posttraumatic stress disorders, we performed further adjustment for these factors.

To improve the distribution properties of all biomarkers, data were transformed to a logarithmic scale. After transformation the 


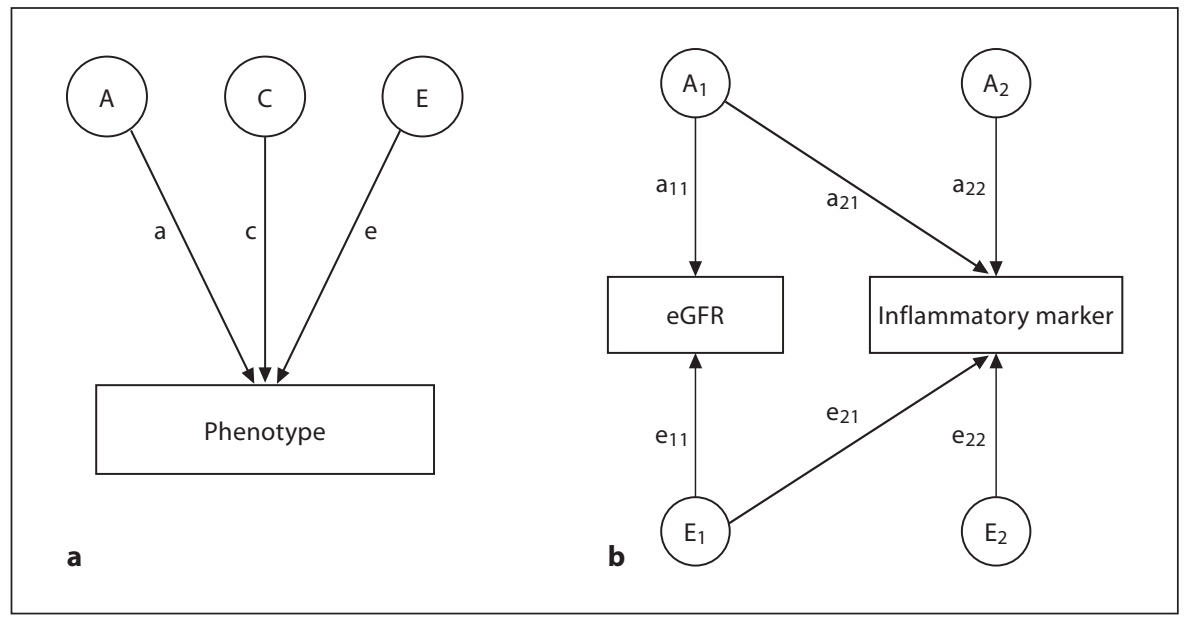

Fig. 1. a Univariate SEM with three latent factors on one measured phenotype. $\mathrm{A}=$ Additive genetic variance component; $\mathrm{C}=\mathrm{com}$ mon environmental variance component; $\mathrm{E}=$ unique environmental variance component; $\mathrm{a}=$ genetic path coefficient; $\mathrm{c}=\mathrm{com}-$ mon environmental path coefficient; $\mathrm{e}=$ unique environmental path coefficient. Heritability $h^{2}=a^{2} /\left(a^{2}+c^{2}+e^{2}\right)$. b Bivariate Cholesky SEM decomposition. A1 = Genetic factor loading on both eGFR and inflammatory marker; A2 = genetic factor loading on inflammatory markers alone; E1 = unique environmental factor

distribution was normalized. Log transformation of the eGFR did not improve its distribution profile; therefore, raw eGFR data were used. A 2-tailed $\mathrm{p}<0.05$ was considered significant. These analyses were performed using STATA 8 (StataCorp, College Station, Tex., USA).

To estimate the relative contribution of genetic and environmental influences on eGFR and inflammatory markers, SEM were constructed using the software package $\mathrm{Mx}$ [15]. The assumptions under twin modeling are that MZ twins share $100 \%$ of their genes whereas DZ twins share, on average, $50 \%$ of their genes. Shared environmental factors are assumed to be $100 \%$ for both $\mathrm{MZ}$ and $\mathrm{DZ}$ twins if siblings were reared together as in our sample. These factors include, for example, family socioeconomic status, childhood environment, prenatal factors (maternal nutrition, other exposures during pregnancy) or other parental factors. The unique environment is not shared between siblings for either MZ or DZ twins, and includes, for example, individual, nonshared exposures in adulthood; it also includes measurement error. Thus, a greater phenotypic similarity in MZ twins as compared with DZ twins, as indicated by a higher correlation in MZ than DZ twins, suggests a genetic influence. Model fitting is based on the comparison of the variance-covariance matrices in $\mathrm{MZ}$ and DZ twin pairs and allows separation of the observed phenotypic variance into additive (A) genetic components and shared (C) or unique (E) environmental components (fig. 1a). To determine the most parsimonious variance components model (ACE, $\mathrm{AE}, \mathrm{CE}$ or $\mathrm{E}$ ) for each of the variables, a series of models were tested. Standard likelihood ratio tests between submodels (AE, $\mathrm{CE}$ and E) and full ACE model were used to assess the importance of each variance component on the fit of the model. The Akaike loading on both eGFR and inflammatory marker; E2 = unique environmental factor loading on inflammatory markers alone; a11-a22 = genetic path coefficients; e11-e22 = unique environmental path coefficients. a $21=0$ indicates that there is no genetic correlation between eGFR and inflammatory marker, and e21 $=0$ indicates that there is no unique environmental correlation. For clarity only genetic (A) and unique environmental (E) factors are illustrated. information criterion was used to determine the optimal fitting model, where a lower Akaike information criterion indicates a more parsimonious and thus a better fitting model. In the most parsimonious model, the ratio of additive genetic variance (A) to total phenotypic variance $(\mathrm{A}+\mathrm{C}+\mathrm{E})$ is defined as heritability $\left(h^{2}\right)$. The univariate SEM models were fit to estimate the heritability for eGFR and inflammatory markers before and after adjusting for covariates.

To examine the hypotheses whether there are genetic and/or environmental factors shared between eGFR and inflammatory markers, bivariate SEM models were then performed. These models fit the association between two traits. The AE Cholesky model is presented in figure $1 b$. By constraining certain path coefficients to zero (fig. 1b), we tested for the significance of (1) the genetic correlation between eGFR and inflammation $(\mathrm{a} 21=0)$ and (2) the unique environmental correlation between eGFR and inflammation $(\mathrm{e} 21=0)$. Significance of all of these models was tested by likelihood ratio tests. $\mathrm{p}<0.05$ was considered significant.

\section{Results}

Of 524 twins (262 pairs), 9 twins were excluded for outliers of inflammatory markers $(n=4)$, outliers of eGFR (improbable eGFR $\left.>150 \mathrm{ml} / \mathrm{min} / 1.73 \mathrm{~m}^{2}\right)(\mathrm{n}=2)$ and missing eGFR $(n=3)$. In total, 515 twins were left for analysis, including 255 pairs (152 MZ and $103 \mathrm{DZ}$ pairs) and 5 unpaired twins resulting from the above exclu- 
Table 1. Subject characteristics in 515 twins, including 255 pairs and 5 singletons

\begin{tabular}{lcc}
\hline Variables & MZ twins & DZ twins \\
\hline Subjects & 309 & 206 \\
Mean age \pm SD, years & $55 \pm 3.0$ & $55 \pm 2.7$ \\
Caucasians & $295(95.5)$ & $198(96.1)$ \\
Mean BMI \pm SD & $29.6 \pm 4.7$ & $29.5 \pm 5.4$ \\
Current smoking & $88(28.5)$ & $43(21.0)$ \\
Diabetes mellitus 2 & $40(13.0)$ & $19(9.3)$ \\
Coronary artery disease & $32(10.4)$ & $22(10.7)$ \\
Hypertension & $154(49.8)$ & $99(48.1)$ \\
B-Blockers & $25(8)$ & $11(5.3)$ \\
ACE-I/ARB & $52(16.8)$ & $42(20.4)$ \\
Aspirin & $75(24.3)$ & $56(27.2)$ \\
Statins & $72(23.3)$ & $48(23.3)$ \\
eGFR, ml/min/1.73 m ${ }^{2}$ & & \\
$\quad$ Mean $(S D)$ & $88.3(12.5)$ & $89.7(13.1)$ \\
$\quad$ Median $(25,75 \%)$ & $88.0(82.0,97.8)$ & $93.8(82.6,97.9)$ \\
\hline
\end{tabular}

Data presented as numbers (\%), unless indicated otherwise. ACE-I/ARB = Angiotensin-converting enzyme inhibitor/angiotensin receptor blocker.

sions. Table 1 shows the clinical and demographic characteristics of the patients enrolled in this study. Their mean age was 55 years, 131 (25\%) were smokers, 54 (10\%) had a history of coronary artery disease, 59 (11.5\%) had diabetes mellitus and 253 (49\%) had hypertension; the prevalence of cardiovascular risk factors was not different between MZ and DZ twins (data not shown). The mean eGFR was $89 \mathrm{ml} / \mathrm{min} / 1.73 \mathrm{~m}^{2}$ (range $35-146 \mathrm{ml} /$ $\left.\min / 1.73 \mathrm{~m}^{2}\right)$.

Table 2 shows the mean serum values of several markers of inflammation and endothelial function. Again, there was no significant difference in serum levels of various markers between MZ and DZ twins (data not shown). Table 3 shows the heritability of markers of inflammation and endothelial activation and eGFR. Data are shown prior to and after adjustment for age, BMI, diabetes mellitus, hypertension, prior coronary artery disease, treatment with aspirin, $\beta$-blockers, statins, ACE inhibitors and angiotensin receptor blockers and, additionally, for major depressive disorders and posttraumatic stress disorder. As shown, eGFR in our patients was equally dependent upon genetic heritability $\left(\mathrm{a}^{2}\right)$ and environmental influences $\left(\mathrm{e}^{2}\right)$. While IL-6R and P-selectin appeared to be highly heritable (68 and 76\%, respectively), ICAM and TNF- $\alpha$ R were moderately heritable (51\% each) after adjustment.
Table 2. Inflammatory markers and markers of endothelial function

\begin{tabular}{lcc}
\hline Variables & MZ twins & DZ twins \\
\hline IL-6, pg/ml & $2.05 \pm 1.7$ & $2.40 \pm 2.8$ \\
IL-6R, pg/ml & $29.6 \pm 9.6$ & $28.0 \pm 7.3$ \\
CRP, $\mathrm{mg} / \mathrm{l}$ & $2.81 \pm 3.7$ & $3.08 \pm 7.0$ \\
$\mathrm{TNF}-\alpha, \mathrm{pg} / \mathrm{ml}$ & $1.5 \pm 0.9$ & $1.5 \pm 1.0$ \\
$\mathrm{TNF}-\alpha \mathrm{R}, \mathrm{pg} / \mathrm{ml}$ & $2.1 \pm 0.6$ & $2.1 \pm 0.6$ \\
$\mathrm{MMP}-2, \mathrm{ng} / \mathrm{ml}$ & $167 \pm 32$ & $166 \pm 43$ \\
MMP-9, ng/ml & $318 \pm 155$ & $298 \pm 159$ \\
P-selectin, ng/ml & $97.3 \pm 31.6$ & $96.9 \pm 36.0$ \\
VCAM, ng/ml & $636 \pm 271$ & $617 \pm 297$ \\
ICAM, ng/ml & $327 \pm 105$ & $308 \pm 103$ \\
Fibrinogen, $\mathrm{mg} / \mathrm{ml}$ & $349 \pm 85$ & $348 \pm 82$ \\
WBC, $10^{3} / \mu \mathrm{l}$ & $6.72 \pm 1.92$ & $6.34 \pm 1.75$
\end{tabular}

$\mathrm{CRP}=\mathrm{C}$-reactive protein; $\mathrm{WBC}=$ white blood cell count.

Table 4 shows the association between eGFR and soluble markers of inflammation and endothelial function. Interestingly, while IL-6R and TNF- $\alpha$ R showed a significant inverse correlation with eGFR, ICAM and P-selectin showed a positive association with eGFR, although the association was only marginally significant for P-selectin $(\mathrm{p}=0.06)$.

The results of bivariate SEM demonstrated that the majority of the association between eGFR and biomarkers was due to unique environmental factors. There were weak albeit significant environmental correlations of eGFR with IL-6R $\left(e_{\mathrm{R}}=-0.21, \mathrm{p}=0.038\right)$, TNF- $\alpha \mathrm{R}\left(\mathrm{e}_{\mathrm{R}}=\right.$ $-0.40, p<0.001)$, and P-selectin $\left(e_{R}=0.15, p=0.051\right)$. However, there were no significant genetic correlations between eGFR and inflammatory markers (IL-6R: $g_{R}=$ $-0.11, p=0.33$; TNF- $\alpha R: g_{R}=-0.05, p=0.65$; P-selectin: $\mathrm{g}_{\mathrm{R}}=0.07, \mathrm{p}=0.42$; ICAM: $\mathrm{g}_{\mathrm{R}}=0.16, \mathrm{p}=0.12$ ). Adjustment for covariates did not change these results (data not shown).

\section{Discussion}

In this study we described the heritability of renal function, estimated via a novel eGFR formula, as well as that of markers of inflammation and endothelial activation in male twins. We also examined for the first time whether the association between renal function and inflammation is due to shared genetic pathways. A classic twin study is considered the more definitive way to assess the relative effect of genetic factors and environment on 
Table 3. Correlations among $M Z$ and $D Z$ twins and heritability estimations for renal function and inflammatory markers

\begin{tabular}{|c|c|c|c|c|c|c|}
\hline Trait & & MZ & $\mathrm{DZ}$ & $a^{2}(95 \%$ CI $)$ & $c^{2}(95 \% \mathrm{CI})$ & $\mathrm{e}^{2}(95 \% \mathrm{CI})$ \\
\hline \multirow[t]{3}{*}{ eGFR } & Unadjusted & 0.50 & 0.31 & $0.51(0.39-0.61)$ & - & $0.49(0.39-0.61)$ \\
\hline & Adjusted $1^{\mathrm{a}}$ & & & $0.50(0.38-0.60)$ & - & $0.50(0.40-0.62)$ \\
\hline & Adjusted $2^{\mathrm{b}}$ & & & $0.48(0.36-0.59)$ & - & $0.52(0.41-0.64)$ \\
\hline \multirow[t]{3}{*}{ IL-6R } & Unadjusted & 0.94 & 0.59 & $0.53(0.32-0.84)$ & $0.39(0.08-0.60)$ & $0.08(0.06-0.11)$ \\
\hline & Adjusted $1^{\mathrm{a}}$ & & & $0.68(0.40-0.89)$ & $0.18(0.00-0.46)$ & $0.14(0.10-0.20)$ \\
\hline & Adjusted $2^{\mathrm{b}}$ & & & $0.68(0.39-0.89)$ & $0.18(0.00-0.46)$ & $0.14(0.11-0.20)$ \\
\hline \multirow[t]{3}{*}{ TNF- $\alpha \mathrm{R}$} & Unadjusted & 0.64 & 0.25 & $0.63(0.50-0.72)$ & - & $0.37(0.28-0.50)$ \\
\hline & Adjusted $1^{\mathrm{a}}$ & & & $0.51(0.36-0.63)$ & - & $0.49(0.37-0.64)$ \\
\hline & Adjusted $2^{\mathrm{b}}$ & & & $0.51(0.36-0.63)$ & - & $0.49(0.37-0.64)$ \\
\hline \multirow[t]{3}{*}{ ICAM } & Unadjusted & 0.58 & 0.10 & $0.55(0.43-0.65)$ & - & $0.45(0.35-0.57)$ \\
\hline & Adjusted $1^{\mathrm{a}}$ & & & $0.51(0.39-0.61)$ & - & $0.49(0.39-0.61)$ \\
\hline & Adjusted $2^{b}$ & & & $0.50(0.38-0.60)$ & - & $0.50(0.40-0.62)$ \\
\hline \multirow[t]{3}{*}{ P-selectin } & Unadjusted & 0.76 & 0.41 & $0.78(0.71-0.83)$ & - & $0.22(0.17-0.29)$ \\
\hline & Adjusted $1^{\mathrm{a}}$ & & & $0.76(0.69-0.82)$ & - & $0.24(0.18-0.31)$ \\
\hline & Adjusted $2^{\mathrm{b}}$ & & & $0.76(0.69-0.81)$ & - & $0.24(0.19-0.31)$ \\
\hline
\end{tabular}

$\mathrm{a}^{2}=$ Genetic component (heritability); $\mathrm{c}^{2}=$ common environmental component; $\mathrm{e}^{2}=$ individual environmental component.

${ }^{a}$ Adjusted for age, race, BMI, current smoking, diabetes, hypertension, coronary artery disease and medications (aspirin, $\beta$-blockers, statins and angiotensin-converting enzyme inhibitor/angiotensin receptor blocker).

${ }^{\mathrm{b}}$ Additionally adjusted for major depressive disorder and posttraumatic stress disorders.

Table 4. Association between renal function and inflammatory markers

\begin{tabular}{|c|c|c|c|c|}
\hline & & eGFR & & \\
\hline & & $\beta$ & $95 \% \mathrm{CI}$ & $\mathrm{p}$ value \\
\hline IL-6R & Unadjusted & -5.22 & $-10.02,-0.41$ & 0.03 \\
\hline & Adjusted $^{\mathrm{a}}$ & -4.98 & $-9.67,-0.30$ & 0.04 \\
\hline & Adjusted $^{\mathrm{b}}$ & -5.04 & $-9.70,-0.37$ & 0.03 \\
\hline TNF- $\alpha \mathrm{R}$ & Unadjusted & -10.60 & $-15.60,-5.60$ & $<0.0001$ \\
\hline & Adjusted $^{\mathrm{a}}$ & -10.81 & $-15.82,-5.80$ & $<0.0001$ \\
\hline & Adjusted $^{\mathrm{b}}$ & -10.30 & $-15.31,-5.28$ & $<0.0001$ \\
\hline ICAM & Unadjusted & 6.65 & $2.72,10.58$ & 0.001 \\
\hline & Adjusted $^{\mathrm{a}}$ & 4.92 & $0.74,9.10$ & 0.02 \\
\hline & Adjusted $^{\mathrm{b}}$ & 5.05 & $0.87,9.23$ & 0.02 \\
\hline P-selectin & Unadjusted & 3.77 & $0.55,6.99$ & 0.02 \\
\hline & Adjusted $^{\mathrm{a}}$ & 2.95 & $-0.16,6.07$ & 0.06 \\
\hline & Adjusted $^{\mathrm{b}}$ & 2.98 & $-0.13,6.10$ & 0.06 \\
\hline
\end{tabular}

a Adjusted for age, race, BMI, current smoking, diabetes, hypertension, coronary artery disease and intercurrent medications (aspirin, $\beta$-blockers, statins and angiotensin-converting enzyme inhibitor/angiotensin receptor blocker).

b Additionally adjusted for major depressive disorder and posttraumatic stress disorder.

Renal Function and Inflammation traits and diseases, since it allows to control for genetic effects as well as common environment [16].

To date the heritability of eGFR has been described in one female twin study and a few sibling and community studies, at times with conflicting results. The heritability of renal function described in our study $(\sim 50 \%)$ is similar to that previously described by Hunter et al. [9] in female twins and Fava et al. [8] in 249 siblings. Bathum et al. [17], on the other hand, failed to demonstrated heritability of serum creatinine in Danish elderly male twins, while they demonstrated a $44 \%$ heritability of the same trait in females. Finally, Fox et al. [18] reported a 33\% heritability of eGFR in 1,224 Framingham Heart Study subjects, while Langefeld et al. [19] described a surprising 75\% heritability of eGFR in 662 patients (422 siblings) with diabetes mellitus type 2 .

Finding a heritable trait is a step toward the discovery of biological pathways that may potentially influence or prevent the development of deadly diseases such as renal failure. In this respect, inflammation has been suggested as an important pathway leading to onset and progression of renal disease. An increase in soluble markers of inflammation and endothelial activation in patients with moderate to severe renal dysfunction (eGFR $<60 \mathrm{ml} / \mathrm{min}$ / 
$1.73 \mathrm{~m}^{2}$ ) has been reported in several prior publications [1-5], although Muntner et al. [20] and Shlipak et al. [1] failed to show an increase in these markers when the eGFR is above $>60 \mathrm{ml} / \mathrm{min} / 1.73 \mathrm{~m}^{2}$. It is interesting to note that an elevation of soluble markers of inflammation has been linked with progression of renal dysfunction $[6$, $7]$ and greater mortality $[21,22]$ in patients with chronic kidney disease but that an increase in several biomarkers with declining eGFR was often not associated with an increase in ICAM $[1,2,4]$. Furthermore, in one report ICAM was elevated in chronic kidney disease patients only in the presence of prior cardiovascular disease [21]. These observations are in line with our findings of an inverse association of eGFR with IL-6R and TNF- $\alpha$ R levels and a positive association of eGFR with ICAM levels. There are 2 potential reasons for this apparently paradoxical finding. Hauser et al. [23] showed that PECAM and ICAM are highly expressed in the renal vasculature and as glomerular disease progresses their production diminishes. Additionally, these cell adhesion molecules could be taken up at the vasculature level as active inflammatory reactions develop with a resultant decrease in serum levels, rather than an increase, as renal function deteriorates.

Our study suggests the absence of a genetic link between inflammation and renal function. The lack of a common genetic pathway between inflammatory mediators and renal function suggests that the increase in inflammatory mediators as renal failure develops is a response to deteriorating renal function, rather than being implicated in the pathogenesis of renal dysfunction. Because we found significant, albeit weak, environmental correlations between eGFR and inflammatory biomarkers, the association between inflammation and renal dysfunction can be due, in part, to shared environmental risk factors between these two conditions.

There were several limitations to this study. First, our sample was derived from a twin registry of military veterans, where the members may have had different environmental exposures compared to other similarly aged individuals. Second, our analyses included only men, thus one should be cautious to extend our results to women. The study design was cross-sectional; for twin studies to be fully informative they should optimally be longitudinal and should have started in early years of life to clearly separate environmental and genetic influences on the outcome of interest. However, such a lifetime twin cohort does not exist in the United States. Finally, only a limited number of patients in this study had advanced renal failure. Nonetheless, our goal was to study the shared heritability of renal function, not renal failure, and inflammation in a population sample, and there was a sufficient spread of eGFR values to make our analyses meaningful. Additionally, preclinical outcome measures, also called intermediate phenotypes, are genetically closer to the pathogenic genotype than the clinical phenotype itself, and are therefore preferred for genetic analyses [24].

In summary, in this twin study IL-6R and P-selectin were highly heritable while renal function, ICAM and TNF- $\alpha$ R were moderately heritable. No common genetic pathway could be detected between renal function and markers of inflammation. These results suggest that increased inflammation is a response to declining renal function rather than a mechanism underlying renal deterioration. Consequently, much of the inflammatory response can be prevented by preventing renal disease. Part of the association between renal dysfunction and inflammation may also be due to shared environmental risk factors between these two processes. These data may be useful in planning preventive strategies to retard or prevent systemic inflammation related to declining renal function.

\section{Acknowledgments}

This study was supported by grants K24HL077506, R01 HL68630, R01 AG026255 (Dr. Vaccarino) from the National Institutes of Health (NIH), Emory University General Clinical Research Center grant MO1-RR00039, and grant 0245115N from the American Heart Association (Dr. Vaccarino). The US Department of Veterans Affairs has provided financial support for the development and maintenance of the VET Registry.

References

-1 Shlipak MG, Fried LF, Crump C, Bleyer AJ, Manolio TA, Tracy RP, Furberg CD, Psaty BM: Elevations of inflammatory and procoagulant biomarkers in elderly persons with renal insufficiency. Circulation 2003; 107: $87-92$.

-2 Stam F, van Guldener C, Schalkwijk CG, ter Wee PM, Donker AJ, Stehouwer CD: Impaired renal function is associated with markers of endothelial dysfunction and increased inflammatory activity. Nephrol Dial Transplant 2003;18:892-898.

-3 Nelson CL, Karschimkus CS, Dragicevic G, Packham DK, Wilson AM, O'Neal D, Becker GJ, Best JD, Jenkins AJ: Systemic and vascular inflammation is elevated in early IgA and type 1 diabetic nephropathies and relates to vascular disease risk factors and renal function. Nephrol Dial Transplant 2005;20: 2420-2426. 
4 Keller CR, Odden MC, Fried LF, Newman AB, Angleman S, Green CA, Cummings SR, Harris TB, Shlipak MG: Kidney function and markers of inflammation in elderly persons without chronic kidney disease: the health, aging, and body composition study. Kidney Int 2007;71:239-244.

$\checkmark 5$ Keller C, Katz R, Cushman M, Fried LF, Shlipak M: Association of kidney function with inflammatory and procoagulant markers in a diverse cohort: a cross-sectional analysis from the multi-ethnic study of atherosclerosis (MESA). BMC Nephrol 2008; 9:9.

-6 Lin J, Glynn RJ, Rifai N, Manson JE, Ridker PM, Nathan DM, Schaumberg DA: Inflammation and progressive nephropathy in type 1 diabetes in the diabetes control and complications trial. Diabetes Care 2008;31:23382343.

$>7$ Tonelli M, Sacks F, Pfeffer M, Jhangri GS, Curhan G: Biomarkers of inflammation and progression of chronic kidney disease. Kidney Int 2005;68:237-245.

$\checkmark 8$ Fava C, Montagnana M, Burri P, Almgren P, Minuz P, Hulthen UL, Melander O: Determinants of kidney function in Swedish families: role of heritable factors. J Hypertens 2008;26:1773-1779.

-9 Hunter DJ, Lange M, Snieder H, MacGregor AJ, Swaminathan R, Thakker RV, Spector TD: Genetic contribution to renal function and electrolyte balance: a twin study. Clin Sci (Lond) 2002;103:259-265.

-10 Su S, Snieder H, Miller AH, Ritchie J, Bremner JD, Goldberg J, Dai J, Jones L, Murrah NV, Zhao J, Vaccarino V: Genetic and environmental influences on systemic markers of inflammation in middle-aged male twins. Atherosclerosis 2008;200:213-220.
11 Goldberg J, Curran B, Vitek ME, Henderson WG, Boyko EJ: The Vietnam era twin registry. Twin Res 2002;5:476-481.

12 Vaccarino V, Brennan ML, Miller AH, Bremner JD, Ritchie JC, Lindau F, Veledar E, Su S, Murrah NV, Jones L, Jawed F, Dai J, Goldberg J, Hazen SL: Association of major depressive disorder with serum myeloperoxidase and other markers of inflammation: a twin study. Biol Psychiatry 2008;64:476483.

13 Levey AS, Stevens LA, Schmid CH, Zhang YL, Castro AF 3rd, Feldman HI, Kusek JW Eggers P, Van Lente F, Greene T, Coresh J: A new equation to estimate glomerular filtration rate. Ann Intern Med 2009;150:604612.

14 Roberts WL: CDC/AHA Workshop on Markers of Inflammation and Cardiovascular Disease: Application to Clinical and Public Health Practice: laboratory tests available to assess inflammation - performance and standardization: a background paper. Circulation 2004;110:e572-e576

15 Neale MC, Boker SM, Xie G, Maes HH: Mx Statistical Modeling, ed 6. Richmond, Virginia Commonwealth University Medical School, 2003.

16 MacGregor AJ, Snieder H, Schork NJ, Spector TD: Twins. Novel uses to study complex traits and genetic diseases. Trends Genet 2000;16:131-134.

17 Bathum L, Fagnani C, Christiansen L, Christensen K: Heritability of biochemical kidney markers and relation to survival in the elderly - results from a Danish population-based twin study. Clin Chim Acta 2004;349:143150.
18 Fox CS, Yang Q, Cupples LA, Guo CY, Larson MG, Leip EP, Wilson PW, Levy D: Genomewide linkage analysis to serum creatinine, GFR, and creatinine clearance in a community-based population: the Framingham Heart Study. J Am Soc Nephrol 2004;15: 2457-2461.

19 Langefeld CD, Beck SR, Bowden DW, Rich SS, Wagenknecht LE, Freedman BI: Heritability of GFR and albuminuria in Caucasians with type 2 diabetes mellitus. Am J Kidney Dis 2004;43:796-800.

20 Muntner P, Hamm LL, Kusek JW, Chen J, Whelton $\mathrm{PK}, \mathrm{He} \mathrm{J}$ : The prevalence of nontraditional risk factors for coronary heart disease in patients with chronic kidney disease. Ann Intern Med 2004;140:9-17.

-21 Stenvinkel P, Lindholm B, Heimburger M, Heimburger O: Elevated serum levels of soluble adhesion molecules predict death in pre-dialysis patients: association with malnutrition, inflammation, and cardiovascular disease. Nephrol Dial Transplant 2000;15: 1624-1630.

$>22$ Suliman ME, Qureshi AR, Heimburger O, Lindholm B, Stenvinkel P: Soluble adhesion molecules in end-stage renal disease: a predictor of outcome. Nephrol Dial Transplant 2006;21:1603-1610.

23 Hauser IA, Riess R, Hausknecht B, Thuringer H, Sterzel RB: Expression of cell adhesion molecules in primary renal disease and renal allograft rejection. Nephrol Dial Transplant 1997;12:1122-1131.

24 Peyser PA, Bielak LF, Chu JS, Turner ST, Ellsworth DL, Boerwinkle E, Sheedy PF: Heritability of coronary artery calcium quantity measured by electron bean computed tomography in asymptomatic adults. Circulation 2002; 106:304-308. 